\title{
TABLE OF CONTENTS
}

Acknowledgements $\ldots \ldots \ldots \ldots \ldots \ldots \ldots \ldots \ldots \ldots \ldots$

Improving Air Traffic Controller Training

Herbert B. Armstrong

The State of Professional Pilot Meteorology

Education: How Much is Enough?

Captain Timothy H. Miner and

Dr. C. Elaine McCoy 


\section{University Aviation Association}

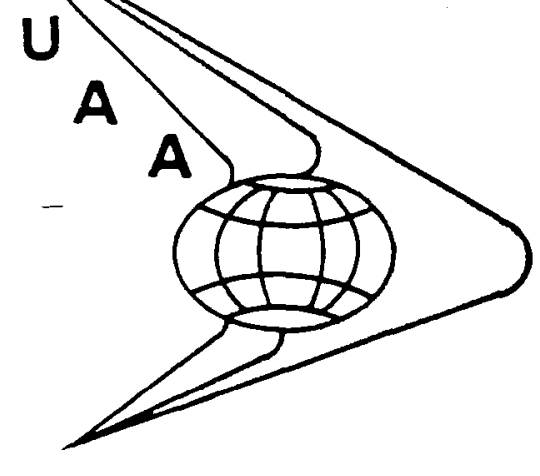

President-Dr. Stacy Weislogel

The Ohio State University President Elect-Dr. Thomas J. Connolly
Embry-Riddle

Aeronautical University

Treasurer-Mr. Ronald D. Kelly

Southern Illinois University

Secretary-Prof. Joan Mace Ohio University

Past President-Mr. William T. Hemphill, Jr. Northeast Louisiana University

BOARD OF TRUSTEES

\begin{tabular}{|c|c|}
\hline $\begin{array}{l}\text { Mr. Herbert B. Armstrong } \\
\text { Hampton University }\end{array}$ & 1991 \\
\hline Dr. Peggy Baty & 1990 \\
\hline \multicolumn{2}{|c|}{ Embry-Aiddle Aeronautical University } \\
\hline Ms. Cassandra J. Bosco & 1991 \\
\hline \multicolumn{2}{|c|}{ National Business Aircraft Association } \\
\hline Mr. Lawrence L. Burian & 1989 \\
\hline \multicolumn{2}{|c|}{ National Air Transportation Association } \\
\hline Dr. Wallace R. Maples & 1991 \\
\hline \multicolumn{2}{|c|}{ Middle Tennessee State University } \\
\hline $\begin{array}{l}\text { Mr. L.L. Ohrt } \\
\text { Metropolitan State Colleo }\end{array}$ & 1990 \\
\hline Mr. Robert H. Ryder & 1989 \\
\hline Delta State University & \\
\hline $\begin{array}{l}\text { Mr. Ray Sancton } \\
\text { Texas State Technical Inst }\end{array}$ & 1989 \\
\hline $\begin{array}{l}\text { Mr. Jason White } \\
\text { White Aviation }\end{array}$ & 1990 \\
\hline
\end{tabular}

\author{
3410 Skyway Drive \\ Opelika, Alabama 36801 \\ (205) 844-2434 \\ FAX (205) 844-2432
}

\section{ACKNOWLEDGEMENTS}

This year's publication of the University Aviation Association (UAA) Proceedings marks the seventh year that papers of scholarly inquiry have been presented to the membership association in this manner. The Proceedings, a unique effort in collegiate aviation, is meant to serve as a vehicle for aviation educators to share the results of their research with members of the profession.

The referee process used in evaluating manuscript submissions is a rigorous procedure. Each submission is blind-reviewed by no less than three individuals who have expertise in that specific field. As has become the policy, selected reviewer comments were shared with contributing authors.

May I congratulate all persons who submitted manuscripts for review this year. The production of a scholarly work requires considerable time and effort. In addition, I wish to thank the individuals who served as reviewers for this year's Proceedings.

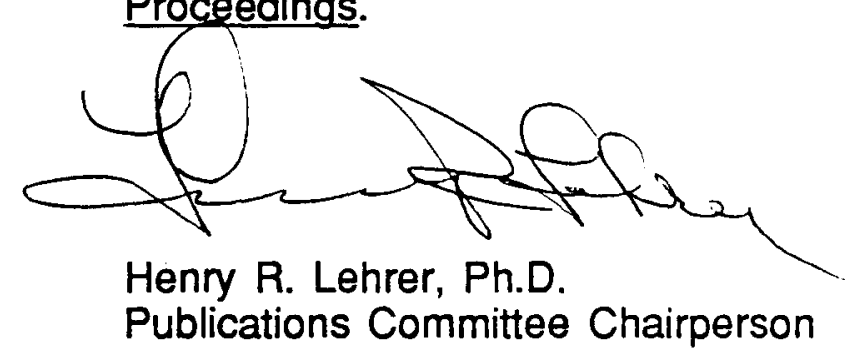


IMPROVING AIR TRAFFIC CONTROLLER TRAINING

Herbert B. Armstrong

Assistant Professor \& Coordinator

Airway Science Program

Hampton University

Hampton, Virginia 
Abstract

In recent years, the nation's air transportation system has undergone a series of profound changes. One aspect of the system which has received some scrutiny is the role of the air traffic controllers and the need to increase the staffing of control facilities. This article examines the field of air traffic control and the characteristics necessary to work in the field. Then, using sound educational and training theory, suggests some ways that air traffic controller training may be improved. 
Over the past decade, the U.S. air traffic control system has undergone a series of unprecedented challenges. Deregulation freed the airlines to expand, creating continually increasing demand. The economic recovery of the mid- and late-1980's combined with low fares to bring thousands more travellers to the ticket counter. In the midst of deregulation, the 1981 PATCO strike reduced the staffing of the system overnight. Today, eight years after the strike, many major air traffic control facilities remain understaffed (Aviation Safety Commission, 21; Mead, 1989, 2-5). In addition, the National Airspace System (NAS) Plan is introducing a new generation of technology and automation which will impose further demands on the system and its personnel (Proctor; Flight Plan for Training, 1-5).

The public perception is that the air traffic system is straining. This perception is exacerbated by reports that near collisions are occurring more frequently and that the margin of safety is growing uncomfortably thin. This perception is not totally accurate. The accident rates for major and national air carriers and for regional carriers continue to decline. The number of reported near mid-air collisions and systems errors (loss of minimum separation between two aircraft under air traffic control) increased sharply between 1983 and 1987. But those increases may be the result of more accurate detection and reporting of errors rather than an actual increased risk (Aviation Safety Commission, 15-17). Nevertheless, one cannot deny that for the next decades the air traffic system faces an environment of change and increasing complexity.

Various groups have offered solutions that range from structural changes, to moving current projects along more quickly, to hiring (or rehiring) more controllers. But no one solution offers a panacea. Air traffic control must be approached as a 
system of interdependent subsystems, each of which faces challenges and problems which will require different, but interrelated, solutions.

While a total solution must address all issues, increasing staffing levels in air traffic control facilities is necessarily an integral part of any solution. Several major facilities are seriously understaffed and the current inflow of new controllers is barely keeping up with the attrition caused by retirements. In recent testimony before the House Subcommittee on Investigations and Oversight, Kenneth M. Mead (1987) of the Government Accounting Office stated that FY 1987 attrition was nine percent higher than trainee hiring at terminals and four percent higher at centers. But increasing staffing levels is not merely a question of hiring more controllers. Controllers must go through an extensive training program during which they learn the complex skills necessary to their job. This is where a major part of the staffing problem lies--the training program as it now exists is insufficient to meet the needs of the system. Several factors contribute to this insufficiency. (For a more detailed discussion of the ATC training issues cited below, see HumRRO 1988.)

First, all controllers must pass through the Federal Aviation Administration Academy at the Aeronautical Center in Oklahoma City. Thus, the limitations of that facility are a major constraint on the number of controllers in the training pipeline. The number of trainees that this single facility can handle becomes the upper limit on the number of new controllers available to the system.

Second, the number of controllers in the pipeline is further reduced by inefficiencies in the Academy program. The Academy is, in fact, not a training program, but rather a screening program (HumRRO, 12; Flight Plan for Training, 35). This approach results in an inordinately high attrition rate during training-- 
averaging more than 41 percent from 1981-1987. Thus, the capacity of the Academy is effectively reduced by half (Mead, 1989, 3; HumRRO, 1984).

Third, since the Academy program is used to screen candidates, the task of actually training new controllers falls to the field facilities (Flight Plan for Training, 5). But understaffing leaves them unprepared to handle the training load. Trainees who survive the Academy screen often face bottlenecks in the field facilities which further slow their progress through the pipeline. Many facilities have a minimal permanent training staff, and smaller facilities have no training staff at all. Trainees are therefore frequently required to guide themselves through training manuals and computer-based instruction without benefits of an instructor (HumRRO, 12-20).

Most facilities lack simulation capability so training must be done on operational positions with live traffic. This precludes the development of incremental training scenarios designed along sound educational principles to facilitate the development of high performance skills. When simulators are available in the field, they are embedded in the facility's operational computers and are therefore unavailable much of the time. Furthermore, they usually have only a few training positions available. Thus, they become additional bottlenecks in the flow of trainees (HumRRO, 12-20).

The training program is not only inefficient, but it is also inadequate. The training provided is not the most appropriate for the types of skills to be developed. The design of the training program must acknowledge certain facts about ATC skills and training strategy that seem to be ignored or, at best, only unconsciously recognized in the present system. Much of what is done in the training program 
seems less related to the nature of the skills required and the type of training needed to learn them than to the legal defensibility of the program (HumRRO, 24).

A major step toward a solution to the problems of the air traffic control system, then, would be to redesign the training system. First, the system can be made more efficient by providing alternatives to the FAA Academy. Second, more training can be accomplished prior to sending trainees to the field facilities. Third, the training can be designed with an understanding of the types of training necessary to develop the kinds of skills a controller needs. By so doing, training will be more appropriate, trainees will progress more rapidly and attain a higher skill level before moving to the field facilities, and the wasteful attrition rates of the past will be significantly reduced.

A training program must be designed around the knowledge and skills it is meant to convey. The selection of instructional strategies, technologies, and approaches will hinge upon what is to be taught and the level of learning to be attained. A hierarchy of learning goals is often used to determine an appropriate educational approach. One such hierarchy is:

1. Knowledge -- recall of information;

2. Comprehension -- understanding how and why;

3. Application -- performing;

4. Analysis -- investigation;

5. Synthesis -- creating new information;

6. Evaluation -- determining the value or accuracy of the information;

7. Knowledge Integration -- performing tasks skillfully.

* (Adapted from Brophy and Good as cited in HumRRO) 
Determining the appropriate level of learning for an instructional program depends on the tasks for which the student is being trained. The initial step in this determination is a job task analysis which makes the functions of the job and the requisite talents explicit.

\section{Functions of an Air Traffic Controller}

An air traffic controller is very much an information processor. The core skills of ATC can be viewed as falling into three main functions: information acquisition, information processing, and output (Figure 1).

The information acquisition function takes place in a dynamic environment which requires the controller to divide and switch attention among multiple sources-pilot transmission, the radar scope, communications with adjacent controllers, weather reports, etc. The controller must constantly adjust to this dynamic environment and new information while checking and updating information continually. He must absorb new information while making decisions.

Decision-making is a part of the second function--information processing. The controller must have a good sense of spatial patterns and time in order to construct a three-dimensional picture of the airspace and the traffic situation. He must apply syllogistic reasoning to project forward from the current situation and make further adjustments according to these projections.

The controller must be able to absorb and process information in order to make crucial decisions quickly and then execute those decisions and/or communicate them to others. This is the output function--putting decisions into action by communicating with pilots and/or other controllers. 
Furthermore, the controller must perform these functions in a "noisy" environment. The context in which the controller operates is replete with distractions, fluctuations between routine and non-routine tasks, short cycle repetition, sporadic time pressure, and demand level variation (Page, 1985; Stein, 1984; Zaitseva \& Tokarev, 1986).

Figure 1.

Noise

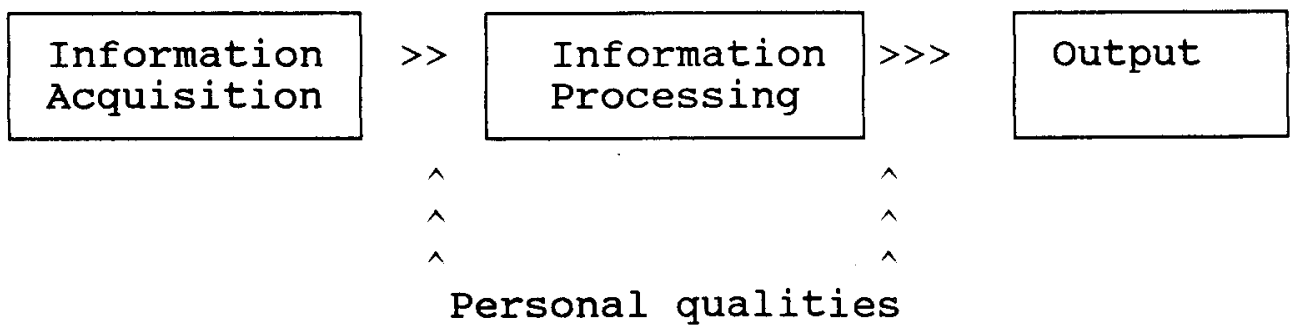

Core Skills

Information acquisition

Divide and switch attention

Multiple sources

Absorb new information while making decisions

Adjust constantly to dynamic situation/new information

Checking and updating information

Information processing

Project forward

Form and maintain three-dimensional picture of airspace

Syllogistic reasoning

Spatial patterns

Time sense

\section{Output}

Develop crucial decisions quickly

Execute decisions

Communicate decisions 
Noise - Context

Sporadic time pressure and demand level

Distractions

Fluctuations between routine/non-routine

Short cycle repetition

\section{Personal qualities}

Syllogistic reasoning ability

Short term recall

Decisiveness and confidence

Conscientiousness/responsibility

Self-control

Ability to work within a team

Ability and willingness to work to set standards.

\section{Acquiring Complex Skills}

The difficult tasks for a controller, then, are planning rather than performance tasks, and they require cognitive rather than psychomotor skills. In order to operate in the noisy environment of ATC, these complex skills must become automatic. Researchers have identified methods to accomplish this.

Human information processing occurs in two fundamental ways. Controlled processing operates in short-term or active memory. It is a relatively slow, serial process which requires little training to develop. It can be considered conscious processing such as we use in decision-making and problem-solving. It is limited by the number of items one can hold in active memory at one time--usually about seven. In order to develop a complex skill, these limits must be overcome (Schneider, undated, 2-5; Schneider and Regian, 3-4; HumRRO, 1-2).

The second type of human information processing is automatic processing resident in long-term memory. Long-term memory holds factual knowledge (which is easily stated and passed on) and procedural knowledge (which is not easily explained without demonstration). Procedural knowledge is automatic processing--it 
is rapid parallel processing requiring little effort, but it does require extensive and consistent training to develop (Schneider, undated, 3-5; Schneider and Regian, 3-4; HumRRO, 2-3).

Air traffic control requires both types of information processing, but automatic processing of procedural knowledge is predominant in the controller's dynamic world. Building these automatic skills requires extensive training following a logical sequence of skill acquisition. The skill must first be decomposed into component tasks which build upon preceding components. Then the student is trained on each component successively. Upon mastering one component, the student moves on to the next, which requires continuing use of the preceding skill while learning the new. This process is called part-task training (Schneider, undated 2-5).

Automatic processing of each skill is developed through consistent developmental steps. First, the procedure is learned as a series of sequential steps, each requiring attention and each taking up the limited space in active memory. This is a level of factual knowledge. With practice, the procedure develops into a coherent unit, gradually taking up less active memory space until it becomes procedural knowledge. At this point, the student can move to the next part-task in the training (Schneider, undated, 4-6; Schneider and Regian, 3-5).

The success of this process depends on the application of several instructional techniques. One technique is to group or "chunk" meaningful information. This helps to overcome the limits of short-term memory by building a smaller number of larger bits of information to be processed. Thus, a telephone number is easier to recall than seven random digits because it is a meaningful chunk of information (HumRRO, 2). 
A second technique is to tie procedures to a discernible event. Activities which are randomized cannot be made automatic. This indicates the importance of learning things in context and tied to a job related outcome (HumRRO, 3).

\section{An Educational Approach for ATC Training}

These principles of human learning lead to an approach to training complex tasks such as air traffic control:

1. Training must be functional and in a job-related context;

2. Training of complex tasks must be broken down into smaller sequences of procedures;

3. These smaller sequences must be learned through large amounts of practice in order to become automatic; and

4. Training must be experiential and performance-related to the greatest extent possible.

This amounts to a part-task training approach which makes extensive use of simulation and automation to supplement rather than replace the instructor. The instructor is necessary to guide student progress, answer questions that arise, demonstrate alternative techniques and procedures, and provide subjective feedback to enhance student progress.

Because of the complex, dynamic nature of the tasks, the lower levels of learning--knowledge, comprehension, and application--are adequate only for initial stages of training. The performance of ATC functions requires the higher levels-analysis of the situation, synthesis of solutions to the situation, and evaluation of the implementation of the solutions on a continuing, real-time basis. 
Under the present training program, application is the highest level reached by most training at the FAA Academy. To some extent, analysis and synthesis are acquired during on-the-job phases of training in the field facilities. Evaluation skills are largely developed through experience, often after the end of formal training. The rather vague concept of "technique" frequently referred to by controllers is perhaps related to the development to evaluative skills.

A well-designed training program following the principles outlined above can be expected to develop more of the higher levels of learning in the training environment prior to the trainee proceeding to the field. A program which utilizes appropriate technology in the way of simulators and interactive training devices can facilitate the development of analytical and synthesis skills. Also, because the development of such a training program will of necessity require that much of the procedural knowledge now implicit in the training be explicated, the process of learning to the evaluative level may also be accelerated. The result will be a controller who is both better trained and at a higher level of learning than is currently possible. 


\section{References}

Aviation Safety Commission. (1988, April). Report to the President (Two volumes).

Brophy, J., \& Good, T. L. (1986). Teacher behavior and student achievement. In M. C. Wittrock (Ed.), Handbook of research on teaching (3rd ed., pp. 328-375). New York: MacMillan Publishing Company. (As quoted in HumRRO)

Federal Aviation Administration. (1989, January). Flight plan for training: FAA training initiatives management plan. FAA Office of Training and Higher Education.

Human Resources Research Organization International, Inc. (HumRRO). (1988, January 28). ATC training analysis study: Design of the next generation ATC training system (Phase I Interim Report).

Mead, K. M. (1987, July). FAA air traffic controller staffing and related issues. Testimony to Subcommittee on Investigations of the House Committee on Post Office and Civil Service, UDAGO.

Mead, K. M. (1989, May). Serious problems continue to trouble the air traffic control work force. Testimony to Subcommittee on Investigations and Oversight, Committee on Public Works and Transportation, House of Representatives.

Page, J. E. (1985, October). Selecting people as air traffic controllers. Presented at CONVEX 85, Guild of ATC Officers, Bournemouth, UK.

Proctor, P. (1988, August 15). FAA academy prepares for advanced ATC systems. Aviation Week and Space Technology, pp. 36-37.

Schneider, W. (Undated Paper). Perceptual training for air intercept control tasks. University of Pittsburgh Learning Research and Development Plan.

Schneider, W., \& Regian, W. (1988). Developing automatic component skills for air intercept controllers (Report No. No0014-86-K-0671). Office of Naval Research.

Stein, E. S. (1984). Controller workload: Past - present - future. 29th Annual ATCA Fall Conference Proceedings.

University of Pittsburgh. (1989, January 11-13). The future of the civil aviation system. Recommendations from a symposium of national aviation leaders.

Zaitseva, E. N., \& Tokarev, V. F. (1985, September). System developed for psychological selection of air traffic controllers. The Controller. 
THE STATE OF PROFESSIONAL PILOT METEOROLOGY EDUCATION: HOW MUCH IS ENOUGH?

\author{
Captain Timothy H. Miner \\ Assistant Professor of Geography \\ Department of Economics and Geography \\ United States Air Force Academy \\ Colorado Springs, Colorado \\ Dr. C. Elaine McCoy \\ Associate Professor \\ Department of Aviation \\ San Jose State University \\ San Jose, California
}


Abstract

In January, 1989, the American Meteorological Society (AMS) sponsored the Third International Conference on the Aviation Weather System. A prevailing theme, "pilot deficiencies in weather education," became the impetus for the Professional Pilot's Meteorology Training Standards Conference held at the United States Air Force Academy, April, 1989.

Many military and civilian organizations, including five University Aviation Association member schools, were represented. The attendees included pilots, meteorologists, trainers, and other educators. Two primary goals of the conference were: (1) to attempt to develop a minimum set of meteorological objectives for all professional pilots, and (2) to initiate dialogue between pilots and meteorologists. The conference confirmed that diversity rules in meteorology education in the professional pilot training curricula. Although a list of objectives was developed, disagreement continues concerning professional pilot needs in terms of meteorology. The true success of the conference was the establishment of a viable network of pilots, meteorologists, and the organizations responsible for pilot training and for providing weather information to pilots. Military and civilian working groups were created, each with a distinct agenda. Participants concur that more communication and cooperation are essential to further define the needs of weather education for professional pilots. 
Introduction

"Pilots don't know enough meteorology." This was the prevailing theme of the Third International Conference on the Aviation Weather System. This conference, sponsored by the American Meteorological Society (AMS), took place in Anaheim, California, January 30 - February 3, 1989.

Dr. John McCarthy was the first keynote speaker. He was chairman of the AMS's Aviation Weather Committee, chairman of the Federal Aviation Task Force on the Aviation Weather System, a leading researcher on microburst phenomena at the National Center for Atmospheric Research, and a private pilot. It was his strong and emphatic conclusion that "pilots don't know enough meteorology."

The second speaker was Captain Patrick Clyne, chairman of the Weather Committee for the Air Line Pilots Association (ALPA) and a captain for Northwest Airlines. He stated that the ALPA Weather Committee had taken a rough sample of the weather knowledge of the ALPA constituency, and once again, "pilots don't know enough meteorology." Other speakers who followed echoed the refrain. Unfortunately, a question which was unfortunately not asked during the question-and-answer session is, what is ENOUGH meteorology for pilots to know?

This paper describes efforts to standardize pilot meteorology training across organizational boundaries, and to answer the question of just how much meteorology should a competent and safe professional pilot know. It also outlines an agenda for future work in this area of pilot education. 
The Current Status of Pilot Meteorology Education

There is wide diversity in pilot meteorology instruction for the professional pilot. The amount and type of instruction is as varied as the sources of trained professional pilots.

\section{Military}

Air Force. The United States Air Force produces about 1200 trained pilots every year. Tasked with a global mission, and with pilots who attain the status of "aircraft commander" very quickly, the Air Force uses only 16 hours to instruct meteorology at its five Undergraduate Pilot Training (UPT) bases. This is the least amount of instruction in meteorology in the history of the Air Force--down from the post World War II high of 50 to 60 hours (Frederick, 1989). This 16 hours consists of reading a study guide and having the 25 lesson objectives reenforced by computer-aided instruction involving page-turning and multiple-choice question exercises with very limited graphics capability. Limited classroom instruction within the 16 hours is given usually by a young instructor pilot who has no more weather instruction than that the students are getting. Also significant is the timing of the course--usually very early in the year-long UPT course. An informal survey by the author using two dozen recent graduates of Air Force UPT found that not one believed that the meteorology instruction was "meaningful or adequate." In two cases, the students thought that they knew more about meteorology than their instructors who were recent graduates of UPT. The knowledge from UPT is supplemented annually prior to the pilot's annual flight review in a locally given class called the Annual Instrument Refresher Course. This one-day instruction period on instrument procedures usually contains one to two hours of instruction on local 
meteorology topics given by a local pilot or the junior weather officer at the base. The topics discussed are locally derived so that there is no opportunity for standardization across the pilot force. Additional weather information may come through additional briefings given at monthly safety meetings but, again, these are locally produced. It appears as though technology and budget constraints are the primary drivers of the meteorology training now given within the Air Force (Frederick, 1989).

Army. The United States Army also produces a large number of professional aviators, most of whom are helicopter pilots. According to Pearson (1989), meteorology training is taught by seasoned civilian instructor pilots in about 30 total hours of classroom instruction. One of the weaknesses of this program is the civilian perspective to meteorology which ignores the military weather information system of Air Weather Service that the young Army aviators will use for the remainder of their career. Although there is no formal refresher training, there are periodic safety meetings addressing local safety topics.

Navy. The United States Navy has the most scientifically derived meteorology course of the three armed services. After an extensive educational testing and evaluation process in 1983, the Navy cut the hours of training in meteorology to about 30 hours. According to Roose (1989), this reduction of some 25 percent allows the trainers (meteorologists) to concentrate on the "important topics"--those with direct application to naval flying. The training is offered in three separate courses that teach meteorology as it applies to the type of flying and skill level of the student pilot. While there was extensive study of the knowledge required by the pilot candidate, no study was conducted on the retention of the 
material after "flying the line." No refresher training is offered to the line pilot, only to the instructor force.

While the military services seem to have a limited training, it is necessary to understand that pilots from all three services have meteorologists immediately available for briefing prior to flight or as close as their radio while in flight. The Navy has the Naval Oceanographic Service and the Army and Air Force have the Air Weather Service.

\section{Civilian}

Pilots who begin their flight careers in the civilian sector enjoy the benefits and suffer the weaknesses of that segment of aviation. While diversity of aircraft, freedom of scheduling, and rate of progression through certificates offer flexibility, that same lack of a standardized system allows unpredictable variation in aviation education. Weather education is no exception.

Sources of flight training and weather education are normally the same. The responsibility for designing, choosing and carrying out a program falls to the individual who must seek available, and usually local, expertise. Alternatives include local FBOs that sometimes provide short-term ground schools, or any of several groups that offer weekend courses for weather or written examinations. An individual approach to weather education can vary from learning the answer to the FAA question pertinent to the written exam for the rating sought, to universities and technical schools that provide a structure and a standard internal to each program. While such programs are an improvement, many variations occur between programs while all the pilots will share the same airspace. 
The professional civilian pilot comes from diverse sources including the military although the number of these crossovers is declining. In civilian aviation, a pilot's personal aviation education history is a factor to be scrutinized. Flight instructors set the tone and act as mentors for their students. Something akin to a genealogy of aviation education occurs as "generations" of values and habits are transmitted both consciously and unconsciously. At times, just as with military courses, the instructors know little more about meteorology than their students (Boudreau, 1989; Carney, 1989; Massey, 1989; McCoy, 1989; Wencel, 1989).

Collegiate programs have more instruction, usually 30 to 60 contact hours, in meteorology than any other type of professional pilot training (Boudreau, 1989). Universities establish curricula that are intended to provide a standard. Still, diversity exists. Some programs incorporate weather only in ground school courses, such as private and instrument ground school courses, and then only minimally. Others require students to obtain additional coursework in meteorology which may or may not be taught by aviation-aware individuals. Yet, others offer aviation weather courses within the discipline including both theory and application. Even these may be taught by experienced or inexperienced weather pilots, and even a course in a given university can vary greatly quarter to quarter with changing instructors.

Among the universities, a diversity of approaches is apparent. Purdue offers a technical approach to meteorology (Carney, 1989). Some schools such as the University of North Dakota (Poellot, 1989) and Metropolitan State College (Boudreau, 1983) utilize atmospheric science departments. Ohio State is an example of a program that offers aviation weather within its major course work as an aviation course. Although some have assumed that most schools use degreed 
meteorologists (Boudreau, 1989), this assumption is questionable. One reason for the diversity of methods is that different groups have unique needs. Meteorologists tend to focus on data interpretation, theory, and displaying the data as products for pilots. This would be true in airlines' weather departments or in the military. Aviation departments tend to offer service and packaging of information for pilots from an aviator's perspective. All too often, the civilian pilot must select, interpret, and apply the information without personal assistance of a meteorologist. Despite the different approaches, colleges and universities seem to be doing the most thorough job teaching future professional pilots meteorology (Boudreau, 1989). But, then, these may be the pilots who will have the greatest need for the greatest knowledge.

Unlike the military, the world of civilian aviation lacks a dedicated, aviation-specific weather service. Airlines provide their own weather departments and private companies are rushing to fill the gaps the retreating National Weather Service and Flight Service Stations leave behind. Many of the system-wide changes are discussed by Skeen (1989).

The military services, collegiate programs, and the local CFI programs all teach future professional pilots. All have different methods which apparently have different results when it comes to teaching meteorology. Since all these pilots fly in the same weather in the same sky, it would seem important to define a standard base of knowledge to ensure that these diverse programs assure a common core of weather knowledge. 
The Professional Pilot's Meteorology Training Standards Conference

The Professional Pilot's Meteorology Training Standards Conference was developed to further study issues that originated at the AMS conference. Held at the United States Air Force Academy in Colorado Springs, Colorado, April 13-14, 1989 , the conference was a multi-organizational effort to renew the study of pilot meteorology.

Previous aviation meteorology conferences include a series of meetings between 1977 and 1985 at the University of Tennessee Space Institute (NASA, 1985; Camp, 1979; Frost, 1978), and the Aviation Weather Forecasting Task Force (1986). But none have provided a definitive list of objectives that explains exactly what knowledge skills need to be taught to the professional pilot.

The conference met for two distinct purposes. The first was to develop the list of objectives that define the professional pilot's basic meteorology skill requirements. The second, and probably more important goal, was to create a dialogue between pilots, meteorologists and educators/trainers. This dialogue would be crucial to understanding the needs of the pilot and the services available from the meteorologist.

Thirty different organizations were represented. Civilian representatives were from the NWS, the FAA, the National Center for Atmospheric Research, the Air Line Pilots Association (ALPA) Weather Committee, the American Meteorological Society, the National Weather Association, United Airlines' Meteorology Department, Transworld Airlines' Meteorology Department, and several schools from the University Aviation Association: Embry-Riddle Aeronautical University (Daytona), Ohio State University, Metropolitan State College (Earth Sciences), and the 
University of North Dakota (Atmospheric Sciences). Purdue University was able to participate substantially by mail. Because of the role the military played in organizing the meeting, there were a large number of Air Force organizations represented including the Air Force Academy (Department of Economics and Geography), the Fourth Weather Wing, the Air Force Instrument Flight Center, Headquarters of the Air Weather Service, the three major flying commands within the Air Force: Strategic, Tactical, and Military Airlift Commands, and members of their respective weather wings. Finally, the Army and Navy had at least one representative at the meeting.

The professional pilot was defined by the conference as any military pilot or any civilian pilot with at least a commercial certificate and instrument rating. "Professional" pilots were the focus of the meeting strictly as a matter of convenience since it was assumed that anyone with that type of designation needed to know "all there was to know" about meteorology.

Statistically, this was an impressive group of individuals to decide just what a pilot needs to know about meteorology. Of the 31 participants, 21 , including 9 of the 11 civilians, were pilots with at least a private airplane rating. Twenty individuals held at least one college degree in meteorology/climatology. Eleven participants were both pilots and meteorologists. Two had a doctorate in meteorology and an ATP.

For most of the day and one-half, the conference participants evaluated objectives for the minimum standard pilot meteorology course. Prior to the meeting, each participant was asked to evaluate a list of learning objectives from the aviation weather course resulting from the Navy's extensive educational assessment study. 
Members were encouraged to add to the list. By the time of the conference, the initial list had grown to over 220 learning objectives (deletions were made only with the group's concurrence). During the keynote addresses, Mr. Kendall Roose from the US Navy briefed the conferees on the methodology that produced the initial list of objectives. The conference as a whole then evaluated a portion of the larger list by deciding whether an objective was "critical", "nice-to-know", or "unnecessary for a professional pilot to know." After an initial combined session so that everyone could "feel out the mood of the collective body," the conference was divided into three working groups that evaluated portions of the remaining list of objectives. "Unnecessary" items were deleted from the list and wording changes were made where necessary.

When not evaluating the ideal course content, the conference attendees were networking in formal sessions which divided members into civilian and military groups, or informally networking over meals. It was during this time that information and course material were exchanged and organizational linkages were created.

The agenda of the conference was designed to accomplish the tasks of identifying the minimum standards for professional pilot meteorology training, and promoting dialogue between individuals and organizations with aviation meteorology training interests.

\section{Limitations to Pilot Meteorology Assessment}

During the conference, function and organizational requirements became evident parameters in limiting the commonality of a solution to just what do professional pilots need to know about meteorology. 
The conference chairman, Captain Miner, presented a diagram explaining a simple relationship between pilots and meteorology. This simple diagram shows the complex nature of studying pilot meteorology training. This diagram is seen in Figure 1.

THE PILOT

TECHNOLOGY

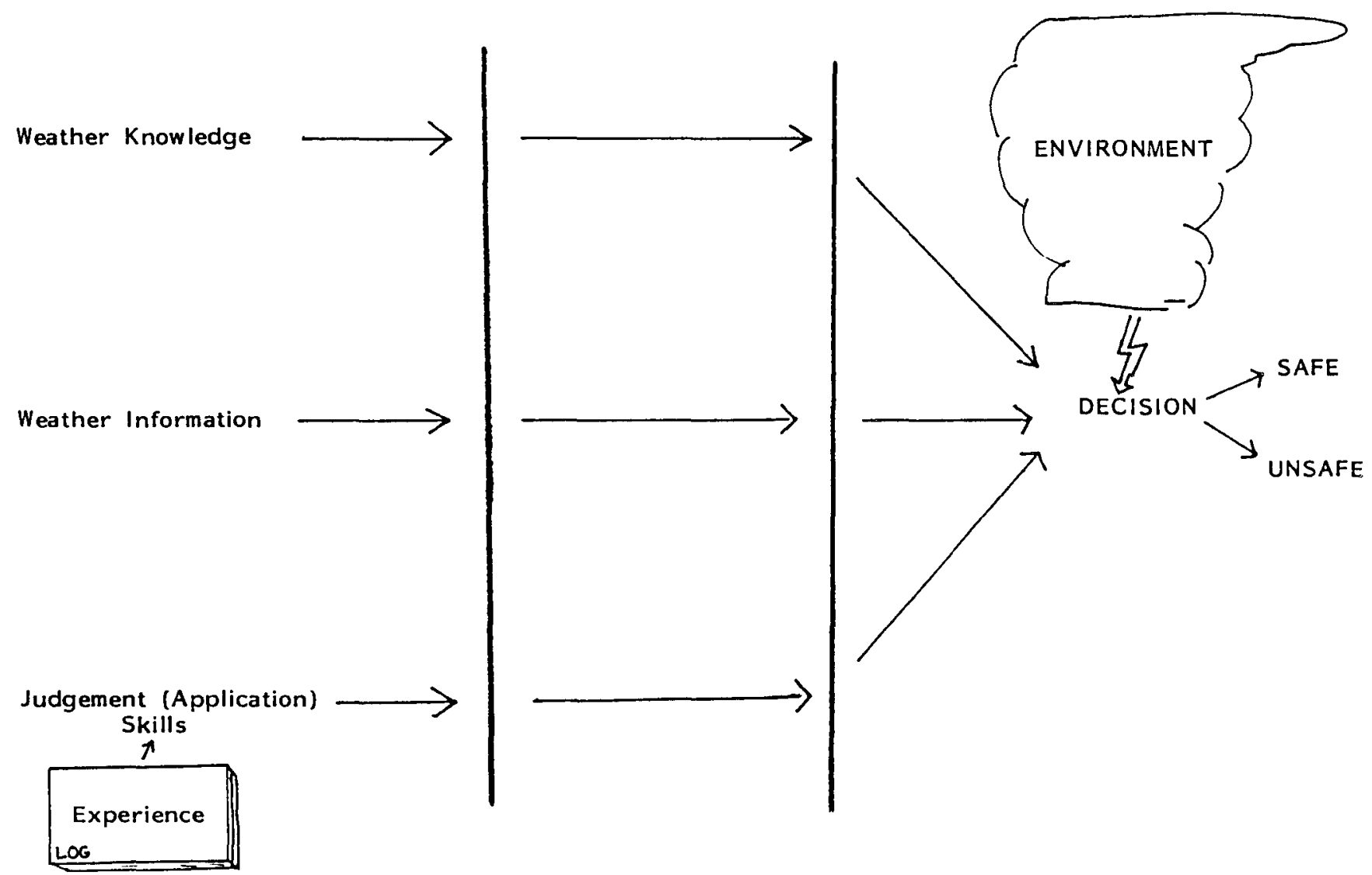

A Simple View of Pilot-Weather Interaction 
The pilot flies with weather knowledge that can be broken into three distinct categories. The pilot has weather theory knowledge (a cold air mass and a warm air mass in contact are a weather front). The pilot may have information on the current state of the atmosphere he or she is about to fly in (the flight path goes through a weather front). And finally, the pilot has a list of rules, both formal and informal, that allow the pilot to apply the knowledge and information with what might be called judgement skills. The latter category is itself influenced by the amount and types of previous experience flying.

At some point within a flight, a pilot must use the judgement skills to use weather theory knowledge and weather information. The result will be a good decision (safe) or a bad decision (unsafe). This decision is forced upon the pilot by the environment.

There are actually three factors that directly influence how the pilot uses his or her three categories of weather knowledge. The most important is the pilot's initial level of training and knowledge in each of the three categories. The next two factors modify the three categories while inflight. The first is the technology available to the pilot. This is the technology of the aircraft (how high can it fly) and the technology available to gather weather information (radar, radio, etc.). The technology available to gather weather information can increase or decrease the level of knowledge that the pilot can use to make decisions. It can also require a greater amount of weather theory knowledge. The second factor that modifies weather knowledge inflight is the perceived mission requirements (passengers on board who expect to be at the destination on time). This last factor can directly impact the ability to use the judgement skills. The beginning level of knowledge in 
each of the three categories plus the two inflight modifiers of technology and perceived mission requirements directly impact the levels of knowledge that the pilot has at his or her disposal to make decisions.

If "pilots don't know enough about meteorology," then what is it that they don't know? What part of the 40 percent of all fatal accidents involving weather are caused by a lack of weather theory knowledge? How many were caused by a lack of current information? In how many accidents did a lack of judgement skills become a cause? How many accidents were influenced by the technology modifier or by the perceived mission requirements of the pilot? These questions show the complex nature of solving the pilot meteorology training problem.

Because no accident statistics can answer these questions, the participants limited their focus to weather theory knowledge. There are a few studies that discuss information (Johnson, 1989) and judgement applications (McCoy, 1989).

\section{Results}

In attempting to accomplish its first goal, the conference found very quickly that there is as divergent a body of opinions on what meteorology should be taught professional pilots as there are differing training programs. Conference participants tended to eliminate suggested lesson objectives that were theoretical in nature (i.e., cyclogenesis and upper-level divergence of the atmosphere). The majority seemed to stress practicality--applied aviation meteorology. Dissent came from the more theoretical practitioners, usually the academic meteorologists. Participants also eliminated objectives that they believed were more operational, e.g., aircraft specific systems such as anti-icing, or techniques such as flying through turbulence. There was also a tendency to concentrate training on using weather information (Boudreau, 
1989). The resulting list contains about 120 objectives of critical and nice-to-know information that the conference established as the baseline for all professional pilot meteorology instruction. Examples of these objectives are found in the appendix.

After the conference, each participant was asked to individually evaluate the conference-produced list of objectives and make personal comments and corrections. As one would expect, there were more additions to the list. Several attendees strongly urged the return of certain objectives that involved decision-making and judgement skills. These application skills and some of the eliminated operational objectives were believed to be critical to the core of teaching a pilot about meteorology. It is evident that this is only the first step in an on-going evaluation process.

The second goal of the conference was to develop relationships among the organizations represented. This was a rousing success. The military attendees formed a Department of Defense Pilot-Meteorology Working Group. This group made a number of recommendations centering on increasing the amount of meteorology training within the Air Force and increasing the exchange of information between military services as well as between the military and civilian programs. The civilian attendees formed a working group which has taken on the name of the Meteorological Education and Training as an Aviation Resource (METAR) Committee. This group is seeking FAA sanctions as an advisory group to help implement changes within the system. Changes would include increased emphasis on weather knowledge required on FAA exams, during check flights, and required by $\mathrm{CFI}$ candidates. Better communication between pilots and meteorologists during the 
training period would be encouraged as well. Both groups have created their own agendas and are working to implement them.

Implications

The Professional Pilot's Meteorology Training Standards Conference was only the first step in what will be an on-going process of communication. Future projects include organizational linkage and studies of existing programs. University weather education programs need to be examined to determine who is teaching and what is being taught. Relationships between aviation and meteorology departments on the same campus should be developed to maximize the potential and to minimize territorial considerations.

The University Aviation Association needs to consider including a meteorology special interest group under the Flight Education Committee or as a stand-alone but recognized group. Tasks yet remaining include the identification of weather education components needed as refresher courses for professional pilots, taking into consideration experience levels. Other questions to be answered are, how can research applicable to aviation be quickly disseminated to the pilots? What are the most appropriate linkages for the organizations involved? The issues are critical. Who will teach what to the pilots of tomorrow? Both instructor qualification and the material must be discussed openly among aviation community members, for it is, indeed, a community of professionals who share in a common concern for the national system and all who fly it. 


\section{References}

Boudreau, R. (1983). Collegiate weather education for pilots. Proceedings of the 9th Conference on Aerospace and Aeronautical Meteorology. Boston: American Meteorological Society.

Boudreau, R. (1989). A report on the professional pilot meteorology training standards conference. National Weather Digest, 14, 18-19.

Camp, D. W., \& Frost, W. (Eds.). (1979). Proceedings: Third Annual Workshop of Meteorological and Environmental Inputs to Aviation Systems (NASA CP-2104). Tullahoma, TN: University of Tennessee Space Institute.

Carney, T. Q. (1989). The current state of meteorological education for aviation professionals and methodologies for enhanced learning. In T. Miner (Ed.), $\underline{A}$ Final Report of the Professional Pilot's Meteorology Training Standards Conference. Colorado Springs: United States Air Force Academy Technical Report.

Aviation Weather Forecasting Task Force. (1986). Final Report of the Aviation Weather Forecasting Task Force. Boulder CO: National Center for Atmospheric Research.

Frederick, G. L., Jr. (1989). U.S. Air Force military aircrew weather training. In T. Miner (Ed.), A Final Report of the Professional Pilot's Meteorology Training Standards Conference. Colorado Springs: United States Air Force Academy Technical Report.

Frost, W., \& Camp, D. W. (Eds.). (1978). Proceedings: Second Annual Workshop on Meteorological and Environmental Inputs to Aviation Systems (NASA CP-2057). Tullahoma, TN: University of Tennessee Space Institute.

Johnson, J. P. (1989). Untold weather. Presentation to the Third International Conference on Aviation Weather System. Anaheim: CA.

Massey, R. J. (1989). Aviation weather training and the professional pilot. Preprints: Third International Conference on the Aviation Weather System. Boston, MA: American Meteorological Society.

McCoy, E. C. (1989). Crosschecks, backdrops, and outs: Practical weather tips from the pro's. In T. Miner (Ed.), A Final Report of the Professional Pilot's Meteorology Training Standards Conference. Colorado Springs: United States Air Force Academy Technical Report.

NASA. (1985). Meteorological and Environmental Inputs to Aviation Systems (NASA CP-2498). Washington, DC: Author. 
Pearson, D. (1989). Position paper on army aviation meteorology training. In T. Miner (Ed.), A Final Report of the Professional Pilot's Meteorology Training Standards Conference. Colorado Springs: United States Air Force Academy Technical Report.

Poellot, M. R. (1989). An approach to improved aviation meteorology education. Preprints: Third International Conference on the Aviation Weather System, Boston: American Meteorological Society.

Roose, K. (1989). U.S. Navy meteorology training. Presentation to the Professional Pilot's Meteorology Training Standards Conference. Colorado Springs: United States Air Force Academy.

Skeen, J. T., Jr. (1989). Career pilot weather training curriculum - a National Weather Service perspective. In T. Miner (Ed.), A Final Report of the Professional Pilot's Meteorology Training Standards Conference. Colorado Springs: United States Air Force Academy Technical Report.

Wencel, F. (1989). Aviation weather training. In T. Miner (Ed.), A Final Report of the Professional Pilot's Meteorology Training Standards Conference. Colorado Springs: United States Air Force Academy Technical Report. 


\section{Appendix}

\section{Conference Revised Meteorology Objectives}

$\left(^{*}=\right.$ Critical Information)

\section{General Structure of the Atmosphere}

* Describe the two lower layers of the atmosphere and their boundary.

State the composition of the atmosphere.

* State the six elements of weather that a pilot may encounter in flight--temperature, pressure, wind, humidity, clouds, precipitation, aerosol.

* State the primary hazards to flight--turbulence, low level wind shear, hail, icing, low ceiling, low visibility, thunderstorm, lightning.

\section{Atmospheric Temperature}

State and define the primary source of all weather as insolation.

Define specific hear and explain how it affects the warming of the earth's surface.

State and define the methods of heat transfer and relate it to convection, turbulence, etc.

* Define the International Standard Atmosphere.

* State the standard lapse rate in Celsius.

- Define density altitude, state its parameters and its effect on aircraft performance including the effects of differential density altitude on recip and jets. 